\title{
Occupational risk and the development of premalignant skin lesions among paraquat manufacturers
}

\author{
J-D WANG, ${ }^{1}$ W-E LI, ${ }^{2}$ F-C HU, ${ }^{1}$ K-H HU ${ }^{2}$ \\ From the Graduate Institute of Public Health, ${ }^{1}$ National Taiwan University, College of Medicine, Taipei, and \\ Department of Dermatology, ${ }^{2}$ Veterans General Hospital at Taichung, Taiwan, Republic of China (100)
}

ABSTRACT The objective of this study was to determine the prevalence rate and possible aetiological factors of premalignant skin lesions observed among paraquat manufacturers. A total of 228 workers in 28 factories were interviewed and independently examined by a dermatologist during site $\bigcirc$ inspection in 1985. Information concerning past working experience, current toxic exposures, other risk factors of hyperpigmented macules and keratosis, and the past and present manufacturing processes of each factory was collected. Sixty nine cases of hyperpigmented macules and 17 of hyperkeratosis were found. Typical macules were irregular in shape, pin head size, hyperpigmented, with or without hyperkeratosis, and usually distributed symmetrically over the forearms, hands, neck, and upper chest, where exposure to sunlight was maximal. Six patients with hyperkeratotic lesions subsequently had biopsies performed and two showed Bowenoid changes. Eighty per cent ( 28 cases) and 67\% (38 cases) of workers developed hyperpigmented macules if they had ever been engaged in bipyridine centrifugation and crystallisation, respectively; there were three workers $3 \%$ with such lesions among those who performed packaging or administrative jobs, or both. There was a significant trend $(p<0.0001)$ for workers to develop hyperpigmented macules and hyperkeratosis the longer they had been exposed to centrifugation or crystallisation, or both, independent of age and the duration of exposure to sunlight. Evidence is presented to suggest that sunlight is a necessary cofactor and that the aetiological agent was produced during high temperature sodium process of bipyridine synthesis, and possibly bipyridine isomer(s).

In June 1983 two workers from a paraquat manufacturing plant visited a dermatological clinic complaining of numerous hyperpigmented macules with hyperkeratotic changes on the parts of the hands, neck, and face exposed to the sun. Specimens showed increased melanin in the basal layer, hyperkeratoses, epidermal hyperplasia, and dysplasia. Some specimens also showed Bowenoid changes. ${ }^{1}$ Since malignant and premalignant skin lesions have been reported among bipyridyl manufacturing workers, ${ }^{2}$ an occupational cause for the skin lesions was strongly suspected. In the present study we report the prevalence rate of hyperpigmented macules and hyperkeratosis among workers in the paraquat manufacturing industry in Taiwan and explore the possible aetiological factors with epidemiological methods.

Accepted 28 May 1986

\section{Methods}

In spring 1985 we visited all the 28 factories engaged in paraquat manufacturing or packaging, or both, to review and examine the manufacturing processes and conditions and interviewed all the workers. Although $\frac{T}{8}$ we made an effort to examine the workers who had already left the factory, the attempt was not success- N ful because many factories did not keep their personnel records for a sufficiently long time. This is, therefore, a prevalence study and we have successfully examined a total of 226 workers.

\section{EXPOSURE HISTORIES}

Each worker was interviewed to provide a detailed work history including past and present exposures to pyridine, bipyridine, dimethyl sulphate, methyl chloride, and paraquat. The workers also provided infor- 
Pyridine recycling

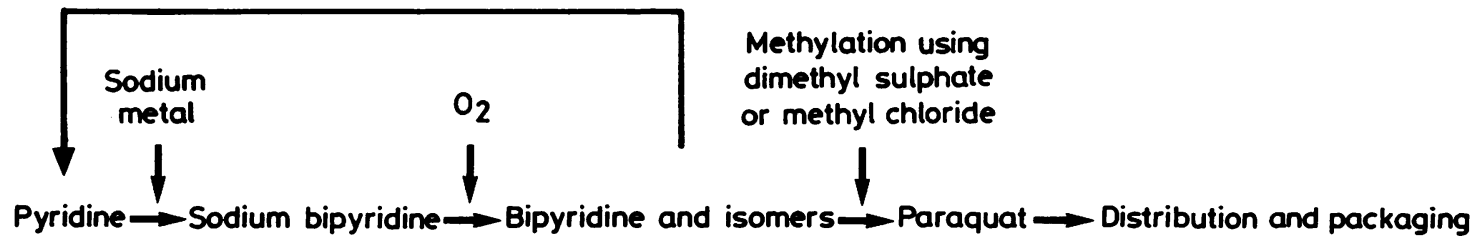<smiles>c1ccncc1</smiles><smiles>c1cc(-c2ccncc2)ccn1</smiles><smiles></smiles>

\subsection{Bipyridine}<smiles>c1ccc(-c2ccccn2)nc1</smiles>

\subsection{Bipyridine \\ Crystallisation Centrifugation}

Flow chart of paraquat manufacturing (high temperature sodium process).

mation about the procedures or processes they were engaged in, and whether or not they used any skin or respiratory protective equipment. Since all factories in Taiwan used only high temperature sodium processes to produce bipyridine ${ }^{2}$ (fig), we classified job categories into 10 different processes and further reduced these into five distinct groups: bipyridine synthesis with and without crystallisation, methylation of bipyridine, packaging, and administration. Informa- tion was also obtained on the duration of normal exposure to sunlight per week and other potential risk factors for dermatological lesions such as exposures to coal tars, pitch, and cutting oils. ${ }^{3}$

\section{OUTCOME ASSESSMENT}

A single dermatologist examined each worker, recording the location and characteristics of any skin lesion and the date of their first appearance. Six cases

Table 1 Number of workers with hyperpigmented macules or hyperkeratosis stratified by job categories

\begin{tabular}{|c|c|c|c|}
\hline Job categories & $\begin{array}{l}\text { No with hyperpigmented } \\
\text { macules }\end{array}$ & No with hyperkeratosis & No of workers checked \\
\hline $\begin{array}{l}\text { All (total) } \\
\text { Only working in: }\end{array}$ & $69(30 \cdot 3 \%)$ & $17 *(7 \cdot 5 \%)$ & 228 \\
\hline $\begin{array}{l}\text { Only working in: } \\
\text { Bipyridine synthesis: }\end{array}$ & \multicolumn{3}{|c|}{ Bipyridine synthesis: } \\
\hline With crystallisation & 4 & 2 & 14 \\
\hline Without crystallisation & 1 & 0 & 3 \\
\hline \multicolumn{4}{|l|}{ Centrifugation after: } \\
\hline Bipyridine crystallisation & 3 & 2 & 3 \\
\hline Methylation of bipyridine & 0 & 0 & 3 \\
\hline Packaging & 2 & 0 & 82 \\
\hline Administration & $\overrightarrow{1}$ & 0 & 7 \\
\hline \multicolumn{4}{|l|}{ Ever working in: } \\
\hline Bipyridine synthesis $\dagger$ & 38 & 9 & 57 \\
\hline Centrifugation after bipyridine synthesis $\uparrow$ & 28 & 10 & 35 \\
\hline
\end{tabular}

*All also had hyperpigmented macules.

† Many workers were simultaneously engaged on these two jobs and they are not mutually exclusive. 
Table 2 Latency period for the development of skin lesions (mean \pm ISD)

\begin{tabular}{|c|c|c|c|}
\hline \multirow[b]{2}{*}{ Joh cutegories } & \multicolumn{3}{|c|}{ Bipyridine crystallisation or centrifugation or both } \\
\hline & Ever & Never & Total \\
\hline \multirow{2}{*}{$\begin{array}{l}\text { No of workers with skin lesions } \\
\text { Age (year) at examination } \\
\text { Mean age (year) of first appearance of lesions } \\
\text { Latency between job entry and the appearance of } \\
\text { lesions (months) } \\
\text { Median } \\
\text { Mode } \\
\text { Range }\end{array}$} & $\begin{array}{l}47 \\
43 \cdot 2 \pm 10 \cdot 7 \\
37 \cdot 9 \pm 12 \cdot 2\end{array}$ & $\begin{array}{l}20 \\
45 \cdot 4 \pm 12 \cdot 3 \\
41 \cdot 7 \pm 13 \cdot 6\end{array}$ & $\begin{array}{l}67^{*} \\
43 \cdot 8 \pm 11 \cdot 2 \\
39 \cdot 0 \pm 12 \cdot 7\end{array}$ \\
\hline & $\begin{array}{l}29 \pm 29 \\
17 \\
12 \\
1-150\end{array}$ & $\begin{array}{l}33 \pm 31 \\
19 \\
12 \\
1-99\end{array}$ & $\begin{array}{l}30 \pm 29 \\
17 \\
12 \\
1-150\end{array}$ \\
\hline
\end{tabular}

*Does not include two workers who could not recall the exact date of first appearance.

were biopsied. Microscopically, mild cases showed an increase of melanin in the basal layer, hyperkeratosis, epidermal hyperplasia, and dysplasia, whereas two more severe cases showed Bowen's disease. Because biopsy was not performed on each worker with skin lesions, we tentatively defined a case as having hyperpigmented macules if these macules were $2-10 \mathrm{~mm}$ in size, irregular in shape, and distributed symmetrically over the forearms and hands, neck, or face or a combination of these. The lesion had also to appear after the worker started to work in a paraquat factory. $\mathscr{\&}$ Furthermore, we defined a case as having hyper- 0 keratosis if workers developed papular lesions (irregular surface) over the hyperpigmented macules.

Table 3 Number of workers with hyperpigmented macules stratified by duration of exposure to centrifugation and crystallisation, duration of exposure to sunlight, and age

\begin{tabular}{|c|c|c|c|c|c|c|}
\hline \multirow[b]{2}{*}{ Exposure to sunlight per week (hours) } & \multirow[b]{2}{*}{ Age } & \multirow{2}{*}{$\begin{array}{l}\text { Hyperpigmented } \\
\text { macules }\end{array}$} & \multicolumn{4}{|c|}{$\begin{array}{l}\text { Duration of exposure to centrifugation and } \\
\text { crystallisation processes (months) }\end{array}$} \\
\hline & & & 0 & $1-6$ & $>6$ & Total $\dagger$ \\
\hline$<4$ & $\begin{array}{l}<31 \\
31-45 \\
46-60 \\
>60\end{array}$ & $\begin{array}{l}\text { Yes } \\
\text { No } \\
\text { Yes } \\
\text { No } \\
\text { Yes } \\
\text { No } \\
\text { Yes } \\
\text { No }\end{array}$ & $\begin{array}{r}0 \\
18 \\
1 \\
21 \\
4 \\
14 \\
0 \\
1\end{array}$ & $\begin{array}{l}1 \\
0 \\
1 \\
2 \\
1 \\
4 \\
0 \\
0\end{array}$ & $\begin{array}{r}0 \\
0 \\
10 \\
0 \\
7 \\
1 \\
1 \\
0\end{array}$ & $\begin{array}{r}1 \\
18 \\
12 \\
23 \\
12 \\
19 \\
1 \\
1\end{array}$ \\
\hline $4-12$ & $\begin{array}{l}<31 \\
31-45 \\
46-60 \\
>60\end{array}$ & $\begin{array}{l}\text { Yes } \\
\text { No } \\
\text { Yes } \\
\text { No } \\
\text { Yes } \\
\text { No } \\
\text { Yes } \\
\text { No }\end{array}$ & $\begin{array}{r}2 \\
15 \\
3 \\
20 \\
4 \\
24 \\
2 \\
1\end{array}$ & $\begin{array}{l}0 \\
2 \\
3 \\
0 \\
0 \\
4 \\
0 \\
0\end{array}$ & $\begin{array}{l}1 \\
0 \\
4 \\
0 \\
3 \\
0 \\
0 \\
0\end{array}$ & $\begin{array}{r}3 \\
17 \\
10 \\
20 \\
7 \\
28 \\
2 \\
1\end{array}$ \\
\hline \multirow[t]{2}{*}{$>12$} & $\begin{array}{l}<31 \\
31-45 \\
46-60 \\
>60\end{array}$ & $\begin{array}{l}\text { Yes } \\
\text { No } \\
\text { Yes } \\
\text { No } \\
\text { Yes } \\
\text { No } \\
\text { Yes } \\
\text { No }\end{array}$ & $\begin{array}{r}2 \\
5 \\
1 \\
11 \\
3 \\
9 \\
0 \\
1\end{array}$ & $\begin{array}{l}2 \\
2 \\
3 \\
0 \\
1 \\
1 \\
0 \\
0\end{array}$ & $\begin{array}{l}0 \\
0 \\
5 \\
1 \\
2 \\
1 \\
2 \\
0\end{array}$ & $\begin{array}{r}4 \\
7 \\
9 \\
12 \\
6 \\
11 \\
2 \\
1\end{array}$ \\
\hline & Total & $\begin{array}{l}\text { Yes } \\
\text { No }\end{array}$ & $\begin{array}{r}22 \\
140\end{array}$ & $\begin{array}{l}12 \\
15\end{array}$ & $\begin{array}{r}35 \\
3\end{array}$ & $\begin{array}{r}69 \\
158\end{array}$ \\
\hline $\begin{array}{l}\chi^{2} \text { (1) (Mantel-Haenszel) } \\
\chi^{2} \text { (1) (Mantel extension for the trend) } \\
\text { Odds ratio: }\end{array}$ & & & & & & $\begin{array}{l}74 \cdot 32^{*} \\
61 \cdot 9^{*}\end{array}$ \\
\hline $\begin{array}{l}\text { Point estimate (Mantel-Haenszel) } \\
95 \% \text { Confidence interval (test based) }\end{array}$ & & & & & & $\begin{array}{r}12 \cdot 5 \\
6 \cdot 7-23 \cdot 4 \\
\end{array}$ \\
\hline \multicolumn{7}{|c|}{$\begin{array}{l}* p<0.0001 \\
+ \text { Does not include one worker with unclassified lesion. }\end{array}$} \\
\hline
\end{tabular}


Table 4 Number of workers with hyperkeratosis and hyperpigmented macules stratified by duration of exposures to centrifugation and crystallisation, duration of exposure to sunlight, and age

\begin{tabular}{|c|c|c|c|c|c|c|}
\hline \multirow[b]{2}{*}{ Exposure to sunlight per week (hours) } & \multirow[b]{2}{*}{ Age } & \multirow{2}{*}{$\begin{array}{l}\text { Keratoses and } \\
\text { hyperpigmented } \\
\text { macules }\end{array}$} & \multicolumn{4}{|c|}{$\begin{array}{l}\text { Duration of exposure to centrifugation and } \\
\text { crystallisation process (months) }\end{array}$} \\
\hline & & & 0 & $1-6$ & $>6$ & Total \\
\hline$<4$ & $\begin{array}{l}<31 \\
31-45 \\
46-60 \\
>60\end{array}$ & $\begin{array}{l}\text { Yes } \\
\text { No } \\
\text { Yes } \\
\text { No } \\
\text { Yes } \\
\text { No } \\
\text { Yes } \\
\text { No }\end{array}$ & $\begin{array}{r}0 \\
18 \\
0 \\
22 \\
0 \\
18 \\
0 \\
1\end{array}$ & $\begin{array}{l}0 \\
1 \\
0 \\
3 \\
0 \\
5 \\
0 \\
0\end{array}$ & $\begin{array}{l}0 \\
0 \\
5 \\
5 \\
1 \\
7 \\
0 \\
1\end{array}$ & $\begin{array}{r}0 \\
19 \\
5 \\
30 \\
1 \\
30 \\
0 \\
2\end{array}$ \\
\hline $4-12$ & $\begin{array}{l}<31 \\
31-45 \\
46-60 \\
>60\end{array}$ & $\begin{array}{l}\text { Yes } \\
\text { No } \\
\text { Yes } \\
\text { No } \\
\text { Yes } \\
\text { No } \\
\text { Yes } \\
\text { No }\end{array}$ & $\begin{array}{r}0 \\
17 \\
0 \\
24 \\
0 \\
27 \\
0 \\
3\end{array}$ & $\begin{array}{l}0 \\
2 \\
0 \\
2 \\
0 \\
4 \\
0 \\
0\end{array}$ & $\begin{array}{l}0 \\
1 \\
3 \\
1 \\
1 \\
2 \\
0 \\
0\end{array}$ & $\begin{array}{r}0 \\
20 \\
3 \\
27 \\
1 \\
33 \\
0 \\
3\end{array}$ \\
\hline \multirow[t]{2}{*}{$>12$} & $\begin{array}{l}<31 \\
31-45 \\
46-60 \\
>60\end{array}$ & $\begin{array}{l}\text { Yes } \\
\text { No } \\
\text { Yes } \\
\text { No } \\
\text { Yes } \\
\text { No } \\
\text { Yes } \\
\text { No }\end{array}$ & $\begin{array}{r}0 \\
7 \\
0 \\
12 \\
0 \\
12 \\
0 \\
1\end{array}$ & $\begin{array}{l}0 \\
4 \\
0 \\
3 \\
1 \\
1 \\
0 \\
0\end{array}$ & $\begin{array}{l}0 \\
0 \\
2 \\
4 \\
2 \\
1 \\
2 \\
0\end{array}$ & $\begin{array}{r}0 \\
11 \\
2 \\
19 \\
3 \\
14 \\
2 \\
1\end{array}$ \\
\hline & Total & $\begin{array}{l}\text { Yes } \\
\text { No }\end{array}$ & $\begin{array}{r}0 \\
162\end{array}$ & $\begin{array}{r}1 \\
25\end{array}$ & $\begin{array}{l}16 \\
22\end{array}$ & $\begin{array}{r}17 \\
209\end{array}$ \\
\hline $\begin{array}{l}\chi^{2} \text { (1) (Mantel-Haenszel) } \\
\chi^{2} \text { (1) (Mantel extension for the trend) }\end{array}$ & & & & & & $\begin{array}{l}38 \cdot 0^{*} \\
49 \cdot 7^{*}\end{array}$ \\
\hline
\end{tabular}

$\bar{p}<0.0001$.

STATISTICAL ANALYSIS

Statistical analysis was performed using the MantelHaenszel summary chi square procedure ${ }^{4}$ and the Mantel extension for the test of trend ${ }^{5}$ using an HP $41 \mathrm{CV}$ calculator with program cards written by Rothman and Boice. ${ }^{6}$

\section{Results}

Among the 226 workers, 69(34.1\%) met our case definition of hyperpigmented macules. Seventeen $(20.2 \%)$ of these 84 workers developed hyperkeratotic changes (table 1). The lesions occurred most frequently among workers engaged in the bipyridine crystallisation and centrifugation processes. Hyperpigmented macules were usually first noticed about one month to one to two years after beginning to work on these processes (table 2). Although three workers with hyperpigmented macules were among the 89 engaged in packaging or administrative jobs, none had hyperkeratotic changes (table 1). There is a significant trend for workers to develop hyperpigmented macules or hyperkeratosis, or both, if they were exposed longer to the processes of crystallisation and centrifugation. The trend is even more obvious when considering the level of exposure at the crystallisation process as half that of the centrifugation process. The trend was consistently present after stratifying by age and duration of exposure to sunlight (tables 3 and 4). Moreover, all the workers with hyperkeratotic change had a history of working at the centrifugation or crystallisation processes or both (table 4).

None of the workers had a history of exposure to other known skin carcinogens with the exception of sunlight. Furthermore, there was no significant association between the occurrence of lesions and age or with normal exposure to sunlight. No worker wore respiratory protective equipment during his work, and there was no association between the wearing of gloves and the occurrence of skin lesions.

\section{Discussion}

The occurrence of premalignant skin lesions among manufacturers of bipyridyl was first reported by Bowra et al in 1982. ${ }^{2}$ The clinical picture in our cases seems similar to theirs, although our cases were gen- 
erally less severe. This may be due to their short exposure. The first paraquat factory in Taiwan was established in 1969 so that there has been an inadequate induction period. Bowra et al speculated, however, that the lesions were probably associated with "magnesium process" because they had only one case working solely in the "high temperature sodium process," and they attributed the lesion to the tarry products produced during bipyridine synthesis. ${ }^{2}$

We have observed several important features that may have aetiological implications. Firstly, all the factories ever manufacturing paraquat in Taiwan used only the high temperature sodium process to synthesise bipyridine, and the cases occurred mainly in workers engaged in the crystallisation and centrifugation of bipyridine; there is a significant doseresponse relation between the duration of exposure and the development of skin lesions. We postulate that the aetiological agent was produced in the high temperature sodium process and that workers were exposed during their work in the processes of crystallisation and centrifugation. Secondly, the lesions were all distributed exclusively over those parts of the body normally exposed to sunlight. They occurred less frequently over the ventromedial aspect of forearms where exposure to sunlight was less but where direct contact with vapours and mists of the byproducts of bipyridine synthesis was most likely. These phenomena indicate that direct contact alone may not produce the skin lesions, and that sunlight is probably a necessary cofactor. Thirdly, the lesions were frequently observed over the face and neck but not over the legs and feet. This suggests that direct skin contact with vapour was probably a more important route of exposure than inhalation. Taken together, these observations suggest that the aetiological agent may be a chemical that evaporates easily in the liquid or solid phase so that workers who were moving rods to enhance crystallisation, or moving the bipyridine crystals into or out of the centrifugation tank, were exposed through direct contact with vapour or mists, or both. Therefore, the molecular weight of this chemical is probably not high, and could be pyridine or any of the isomers of the bipyridines.

The possibility that paraquat is the aetiological agent is low because previous studies among paraquat formulators, ${ }^{7}$ spraymen, ${ }^{8-10}$ and packaging workers $\frac{3}{\Phi}$ has not showed similar hyperkeratotic skin lesions. Chemical analysis of the dark brown liquid and $\overrightarrow{\vec{F}}$ vapour taken from the crystallisation tank by our colleagues and others ${ }^{11}$ showed the presence of $\frac{C}{\square}$ 2,2-bipyridine, 4,4-bipyridine, and other isomers. $\overline{\bar{s}}$

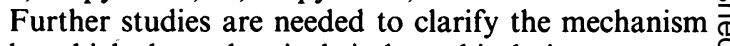
by which these chemicals induce skin lesions.

We thank Drs David Wegman and Michael Malison $\vec{\circ}$ for their constructive comments.

This study was supported by a special grant from the Department of Health, Executive Yuan, Republic of China.

\section{References}

1 Li WM. Premalignant skin lesions associated with occupational 윽 exposure during the manufacture of herbicide paraquat. Dermatologica Sinica 1984;2:1-8.

2 Bowra GT, Duffield DP, Osborn AJ, Purchase IFH. Pre- ฏ malignant and neoplastic skin lesions associated with $\frac{\widehat{\rho}}{\partial}$ occupational exposure to "tarry" byproducts during manu- " facture of 4,4'-bipyridyl. Br J Ind Med 1982;39:76-81.

3 Scotto J, Fraumeni JF Jr. Skin (other than melanoma). In: Schottenfeld D, Fraumeni JF Jr, eds. Cancer epidemiology and prevention. Philadelphia: WB Saunders, 1982:996-1011.

4 Mantel N, Haenszel W. Statistical aspects of the analysis of data from retrospective studies of diseases. $J$ Natl Cancer Inst 1959;22:719-48.

5 Mantel N. Chi-square tests with one degree of freedom: exten- ำ sions of Mantel-Haenszel procedure. Journal of the American Statistical Association 1963;58:690-700.

6 Rothman KJ, Boice JD Jr. Epidemiologic analysis with a pro- $\overline{\bar{O}}$ grammable calculator. Boston: Epidemiological Resources, 3 Inc, 1982.

7 Howard JK. A clinical survey of paraquat formulation workers. Br J Ind Med 1979;36:220-3.

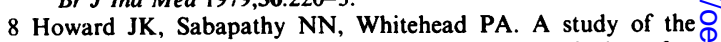
health of Malaysian plantation workers with particular refer- $\frac{}{3}$ ence to paraquat spraymen. Br J Ind Med 1981;38:110-6.

9 Chester G, Woolen BH. Studies of the occupational exposure of Malaysian plantation workers to paraquat. $\mathrm{Br} J$ Ind Med 1981;38:23-33.

10 Hearn CED, Keir W. Nail damage in spray operators exposed to paraquat. $\mathrm{Br} J$ Ind $\mathrm{Med}$ 1971;28:399-403.

11 Wu TC, Kou CL, Lee CD. Studies on some properties of herbi- 음 cide paraquat manufacturing wastewater. Proceedings of the 7th conference on wastewater treatment technology in the 음. Republic of China, September 1982. Taipei: Chinese Institute of $\mathrm{N}$ Civil and Hydraulic Engineering, 1982:621-31. 